\title{
ROAD ACCESSIBILITY PROBLEM AS PART OF LAND CONSOLIDATION PLANNING
}

\author{
Jaroslaw Janus, Piotr Bozek, Jaroslaw Taszakowski, Agnieszka Glowacka \\ University of Agriculture in Krakow, Poland \\ j.janus@ur.krakow.pl, a.glowacka@ur.krakow.pl, p.bozek@ur.krakow.pl, \\ j.taszakowski@ur.krakow.pl
}

\begin{abstract}
Land consolidation is an implement, which allows the rearrangement of spatial structure in rural areas leading to their socioeconomic development. However, the process is costly and time consuming. The needs for land consolidation always exceed the actual possibility of its implementation, therefore it is essential to develop tools, which identify areas of high priority for such investments. Most often they are based on multi-criteria spatial analyses, which include a number of parameters defining agricultural production area. One of the factors that encourages consolidation implementation is the problem of road network accessibility from plots and parameters of transportation network density. Most often, they are studied along with existing land fragmentation indices. The article describes a possible methodology of numerical representation of the intensity of public road inaccessibility from lands based on cadastral dataset analysis. And an important feature of the solution is that it allows working with areas of any size, what makes it possible to use it in studies on regional and central level. The analysis is presented on an example from southern Poland - the Malopolska region with the area of $15182 \mathrm{~km} 2$. The results show a very large diversity of the values of the indices proving their usefulness in the process of identifying areas, which require land consolidation and the process of locating constructions that that improve road accessibility. The results were used by the local authorities during the creation of the spatial information regional system for Malopolska.
\end{abstract}

Keywords: rural areas, cadastre, land fragmentation, road network.

\section{Introduction}

The spatial structure parameters for arable lands have a crucial influence on the conditions of agriculture [1], including its profitability [2]. Some of the most undesirable conditions of spatial structure are the unfavorable index of land fragmentation [3], incorrect structure of farming areas and insufficient agricultural road network. Complex changes of village spatial structure can be achieved through land consolidation [4], but its implementation is very expensive. It can only include limited area and the size of completed consolidation works is always below the real needs. Consequently, the importance of correct land consolidation planning [5] becomes evident. Proper localization of consolidation works is complicated, and the process requires operating with numerous factors [6], which include the most commonly used land fragmentation indices and assessment of the possible effects [7].

One of the factors used in the process is the problem of agricultural road network inaccessibility. It is undeniable that the network is one of the key components required for proper functioning of rural areas [8-9]. The lack of road access indirectly indicates excessive land fragmentation. It also leads to considerable difficulties in farming (including actual material losses of the owners). Finally, no access to farmlands is sometimes regarded as an element that affects complex assessments of land fragmentation [10]. The identification of transportation network in rural areas can be achieved with the use of various techniques, with cadastral data being the most common. There are also methods based on the analysis of aerial or satellite data [11].

The work has the following aims: 1 . To describe the essence of the phenomenon of road inaccessibility from farmlands and its large impact that results from the scale of its occurrence. 2. To explain the index that describes the intensity of the phenomenon and the possible use of the index during the identification of areas in which land consolidation works could be implemented as well as during the assessment completed works of this type. 3. To show the functioning of the findings with the use of data from a large area in Southern Poland, which is characterized by considerable diversity of farm spatial structure attributes affecting agricultural production.

\section{Study area}

The area analyzed in the study represents one of the regions in Southern Poland named Malopolska (Lesser Poland Province). The area of the region is $15182 \mathrm{~km} 2$ and it is composed of over 2000 villages, towns and cities. The number of villages equals 1849 and they are the subject of this 
analysis. The total number of plots in this case is around 4.5 million. Figure 1 shows the location of the study area.
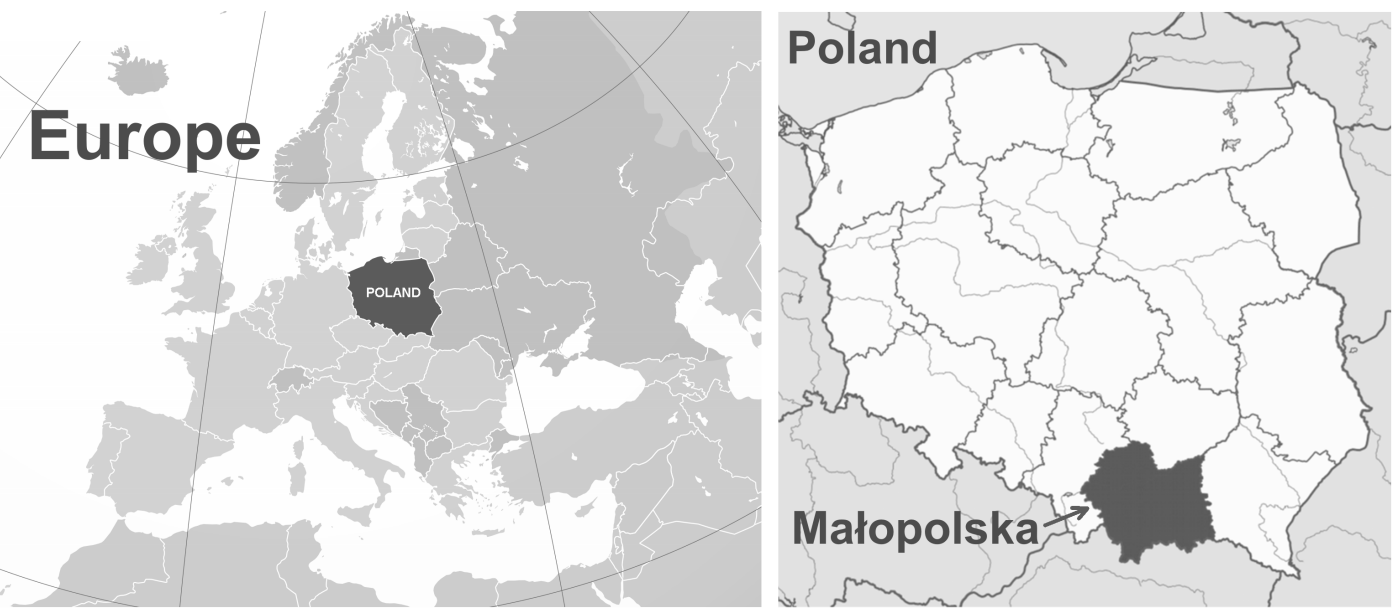

Fig. 1. Malopolska Province in Europe and in Poland

\section{Methods}

The analysis was based on cadastral databases, which in addition to the geometry of a plot, contain the information on its use. The first stage of computation process is the identification of official transportation network for every village in the study area. This category of roads includes those owned by the state or local government units. At the same time, the roads are recognized as separate cadastral plots. Roads of this type provide official, direct access to fields, but their technical standard and type of surface have no significance in the analysis. Unofficial roads (passages through private lands without public road status and not recognized as separate cadastral objects) are excluded from the analysis as they should be eliminated during consolidation works and replaced with the official ones, which guarantee direct access. Mkscal software was used during this stage. It is a tool that supports planning, realization, and assessment of consolidation works [12]. A set of plots that was generated during this stage underwent a verification based on aerial photographs. The purpose of the verification was to add information on the missing elements in the road plots and to correct errors in their identification caused by invalid cadastral records. After verification, it was possible to identify plots with no direct access to the official road network. An example of such network as well as a set of plots identified on its basis is shown in Figure 2. The area covers around $530 \mathrm{~km} 2$. It represents a section on one of the districts, an administrative unit lower than a province.
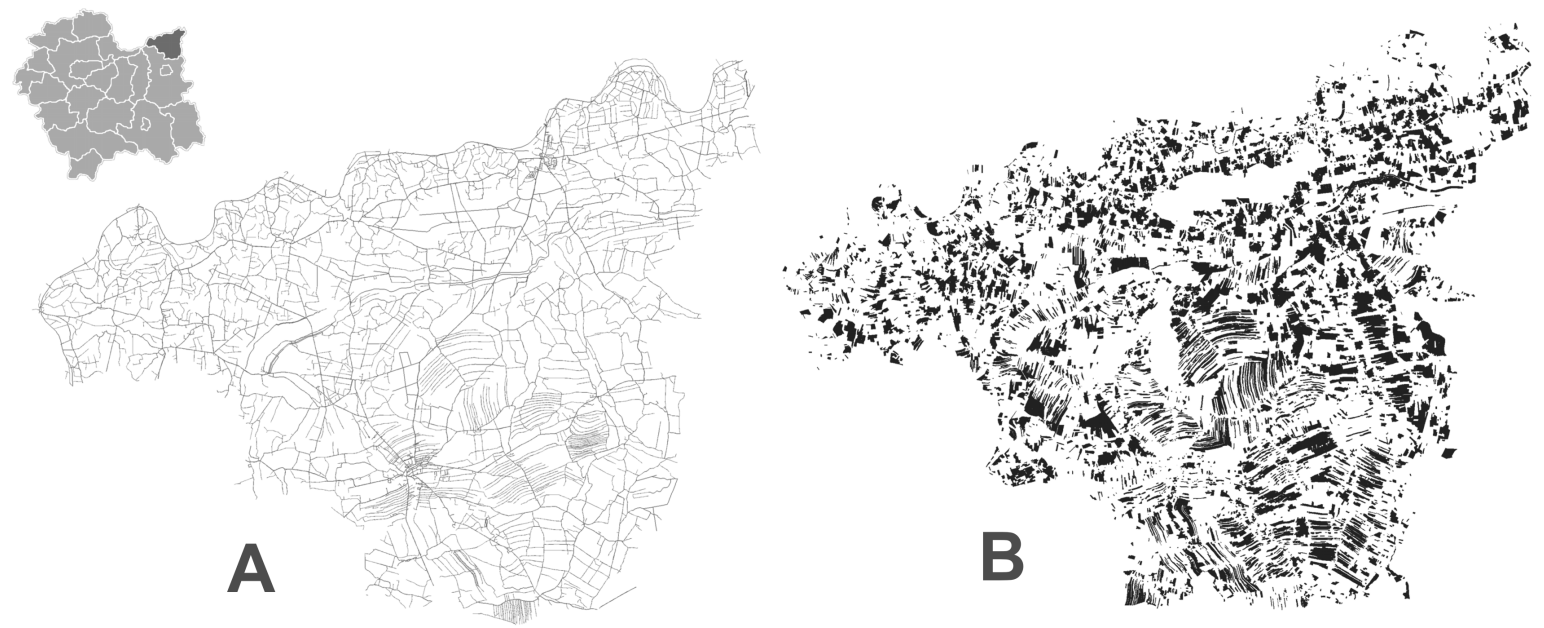

Fig. 2. Example of isolated set of plots which identifies transportation network and the resulting set of plots with no access to the network 
Because the aim of the data analysis was to assess the suitability of the areas for consolidation works, the set of plots with no access to roads was limited to the areas, which are crucial in the process of land consolidation. Therefore, forested areas, transportation areas and water bodies were excluded. Similarly were excluded the state-owned lands, lands belonging to local governments, lands belonging to companies and other institution. Taking all this into account and based on current results of the analysis, two indices can be formulated, which include the intensity of the occurrence of plots with no access to roads. The first one includes the number of plots affected by this problem.

$$
W_{1}=\frac{A}{B} \cdot 100
$$

where $A$ - number of plots with no road access,

$B$ - total number of plots, (values A and B consider suggested exclusions).

Index $W_{1}$ is expressed as percentage. It then undergoes the process of normalization according to the following equation:

$$
W_{1}^{\prime}=\frac{W_{1}-\arg \min \left(W_{1}\right)}{\arg \max \left(W_{1}\right)-\arg \min \left(W_{1}\right)} \cdot\left(n e w_{\max }-n e w_{\min }\right)+n e w_{\min }
$$

Using the value of $n e w_{\min }=0$ and $n e w_{\max }=100$ we receive the ultimate range of the value for the $W^{\prime}{ }_{1}$ index reaching from 0 to 100.

The second partial index includes the aspect of the area of lands with no road access, described with the equation:

$$
W_{2}=\frac{C}{D} \cdot 100
$$

where $C$ - area of plots with no access,

$D$ - total area of plots, (values A and B like before, consider suggested exclusions).

The index, after normalization, is symbolized with $\mathrm{W}_{2}{ }_{2}$ and has a range from 0 to 100 . Using the two partial indices, it is possible to construct a synthetic index that covers the previously explained aspects. It is achieved by the additions made for individual ranges of the values of partial indices. The result is symbolized with $\mathrm{W}_{3}$ and it is normalized as shown in the equation (2) and for the synthetic index the values also range from 1 to 100 .

\section{Results and discussion}

The basic characteristics of the indices are shown in Table 1. The results of the analysis are shown in two figures. Figure 3 shows spatial differentiation of partial indices values (before normalization) in Malopolska Province. Figure 4 shows the differentiation of the synthetic index and the function of 5 datasets: two before and three after normalization. To achieve this, the kernel density estimation method was used, which is based on the Gaussian kernel [13].

Basic characteristics of the analyzed datasets

\begin{tabular}{|c|c|c|c|c|c|}
\hline Variable: & $\boldsymbol{W}_{\mathbf{1}}$ & $\boldsymbol{W}_{\mathbf{1}_{\mathbf{1}}}$ & $\boldsymbol{W}_{\mathbf{2}}$ & $\boldsymbol{W}_{\mathbf{2}}$ & $\boldsymbol{W}_{\mathbf{3}}$ \\
\hline $\begin{array}{c}\mathbf{P}_{\mathbf{3}} \\
\text { Population of } \\
\text { group }\end{array}$ & 1845 & 1845 & 1845 & 1845 & 1845 \\
\hline $\begin{array}{c}\text { Arithmetic } \\
\text { mean }\end{array}$ & 19.66 & 32.11 & 16.66 & 25.40 & 30.13 \\
\hline Median & 16.98 & 27.74 & 14.23 & 21.70 & 25.69 \\
\hline $\begin{array}{c}\text { Standard } \\
\text { deviation }\end{array}$ & 11.95 & 19.53 & 11.45 & 17.46 & 19.03 \\
\hline $\begin{array}{c}\text { Mean standard } \\
\text { error }\end{array}$ & 0.28 & 0.45 & 0.27 & 0.41 & 0.44 \\
\hline Skewness & 0.84 & 0.84 & 0.99 & 0.99 & 0.89 \\
\hline Kurtosis & 0.21 & 0.21 & 0.80 & 0.80 & 0.44 \\
\hline
\end{tabular}



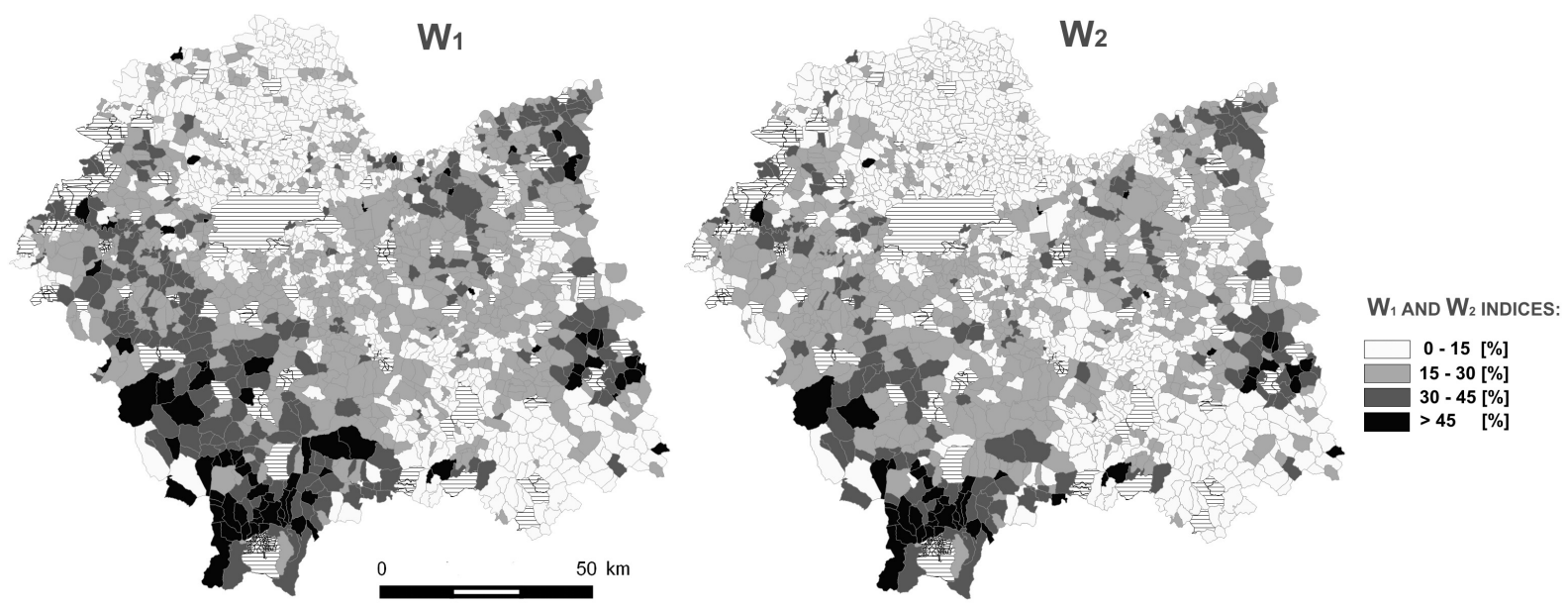

Fig. 3. Spatial differentiation of $\mathrm{W} 1$ and $\mathrm{W} 2$ partial indices values expressed as percentages (before normalization)
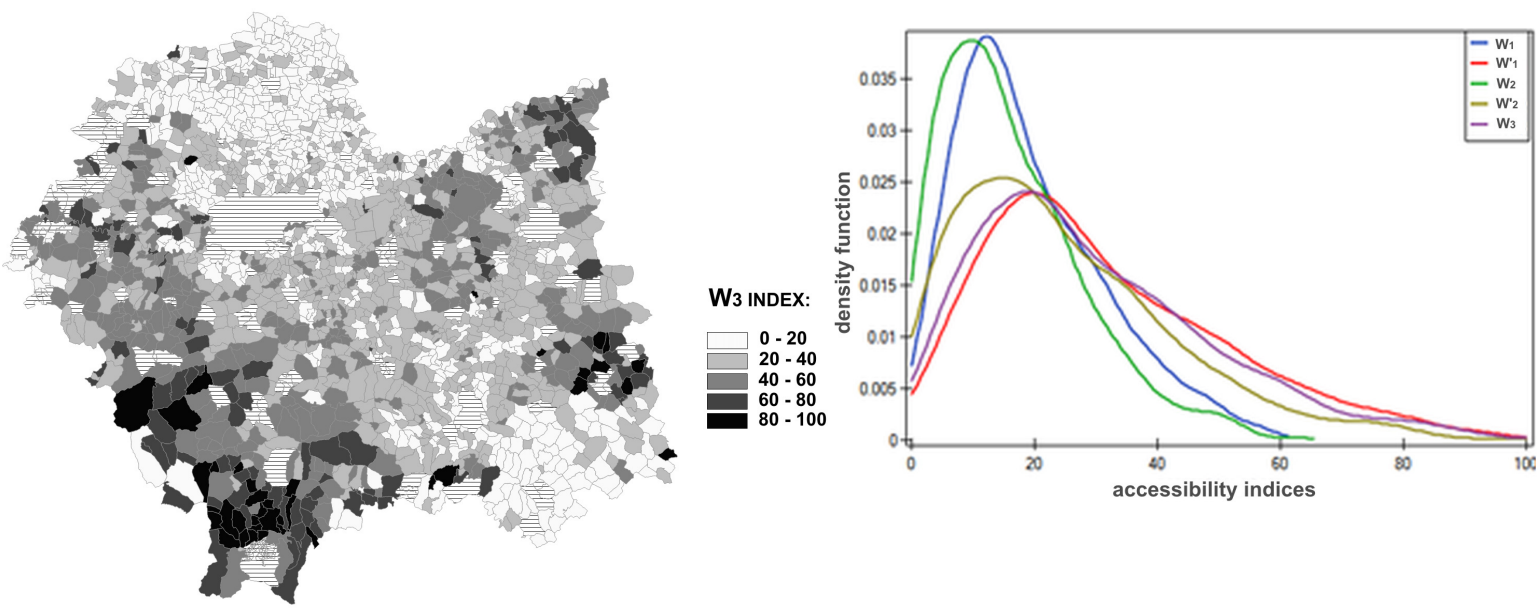

Fig. 4. Spatial differentiation of $\mathbf{W 3}$ synthetic index and different characteristics of datasets before and after normalization

The results show that the problem of road inaccessibility varies greatly in the study area. In the group of almost 2000 villages, it reaches from a couple- to nearly $70 \%$, both in quantitative and areal aspect. The distributions of the density function, both before and after normalization, have high probability what is also visible in maps that represent spatial differentiation of the phenomenon. The output indices, which show the results as percentages, indicate areas where the problem affects the functioning of farms significantly, leading to changes in land use: either abandonment or transformation from arable land to grassland. In these cases road accessibility is of smaller importance.

The high value of the calculated synthetic index or sub-indices (areas represented by the darkest colors in Figures 3 and 4) predispose a given area to consolidation works, because only in this way the problem of no road access can be solved effectively. In practice, this factor should be one of a number of elements taken into account when constructing synthetic indicators with factors that characterize land fragmentation or soil quality.

\section{Conclusions}

The results prove that it is necessary to define the lack of access from plots to roads as a factor that differentiates the areas that can be qualified for consolidation works. It should be an element of multi-criteria spatial analyses. The weight function of this element should be determined every time 
with regards to local priorities. The study, completed for a large area, shows that nondependent use of indices that capture the occurrences of the phenomenon is possible and either the number of plots or the area can be taken into account because the characteristics of their variations are similar. Therefore, in this case the need for synthetic indices can be questioned, as there are partial indices, which are easier to create and they can give equally accurate results.

\section{References}

1. Bentley W. Economic and ecological approaches to land fragmentation: In defence of a muchmaligned phenomenon. Annual Review of Anthropology, 16, 1987, pp. 31-67.

2. Blarel B., Hazell P., Place F., Quiggin J. The economics of farm fragmentation: Evidence from Ghana and Rwanda. World Bank Economic Review, 6(2), 1992, pp. 233-254.

3. King R., Burton S. Land fragmentation: Notes on a fundamental rural spatial problem. Progress in Human Geography, 6(4), 1982, pp. 475-494

4. Hartvigsen M. Land consolidation in Central and Eastern Europe - integration with local rural development needs. 2016 World Bank Conference on Land and Poverty. The World Bank Washington DC, March 14-18, 2016

5. Janus J., Taszakowski J. The idea of ranking in setting priorities for land consolidation works. Geomatics, Landmanagement and Landscape No. 1/ 2015, pp. 31-43.

6. Wang Q., Jin X., Zhou Y. A GIS-embedded system for land consolidation project location: Spatial optimization and fuzzy evaluation. 18th International Conference on Geoinformatics, Beijing, 2010, pp. 1-6.

7. Yang X., Jin C., Zhou Y. Research on the choice of the planning project of the land consolidation project based on comprehensive benefit evaluation. International Conference on Remote Sensing, Environment and Transportation Engineering, Nanjing, 2011, pp. 3399-3402.

8. Jaarsma, C.F. Sustainable Land Use Planning and Planning of Rural Road Networks. Agricultural Engineering International: the CIGR Journal of Scientific Research and Development. Vol. II, 2000.

9. Spooner P.G. Minor rural road networks: values, challenges, and opportunities for biodiversity conservation. Nature Conservation 11: pp. 129-142 (28 Jul 2015)

10. Demetriou D., Stillwell J., See L. A New Methodology for Measuring Land Fragmentation. Computers, Environment and Urban Systems, 39, 2013, pp. 71-80.

11. Hedman K., Hinz S., Stilla U., Road Extraction from SAR Multi-Aspect Data Supported by a Statistical Context-Based Fusion, 2007 Urban Remote Sensing Joint Event, Paris, 2007, pp. 1-6.

12. Janus J. Zygmunt M. (2016). MKSCAL - system for land consolidation project based on CAD platform- Geomatics, Land management and Landscape 2/2016 p. 49-59

13. Silverman, B. Density estimation for statistics and data analysis. Chapman and Hall, 37(1), 1986, pp. 1-22. 